\title{
Performance Pay and the Gender Wage Gap: Evidence from Spain *
}

\author{
Sara de la Rica*, Juan J. Dolado** \& Raquel Vegas ${ }^{* * *}$ \\ (*) Universidad del País Vasco, FEDEA \& IZA \\ ${ }^{(*)}$ Universidad Carlos III \& CEPR \& IZA \\ ${ }^{(* *)}$ FEDEA
}

This draft: June 25, 2010

\begin{abstract}
This paper uses detailed information from a large wage survey in 2006 to analyze the gender wage gap in the performance-pay (PP) component of total hourly wages and its contribution to the overall gender gap in Spain. Under the assumption that PP is determined in a more competitive fashion than the other wage components, one would expect, in principle, to find a low gender gap in PP. However, this is not what we find. After controlling for observable differences in individual and job characteristics as well as for non random selection, the adjusted gender gap in PP reaches $26 \mathrm{log}$ points, displaying a "glass ceiling" pattern. After examining several alternative theories that could rationalize these findings, we conjecture that monopsonistic features, possibly related to women's lower labour mobility due to housework, fit better with our results than other theories related to occupational segregation.
\end{abstract}

JEL Classification: J31, J33, J42, J71.

Keywords: performance pay, gender gaps, selection bias, quantile regressions

\footnotetext{
* This paper was prepared for the 2010 FEDEA Monograph Annual Conference on Talent, Effort and Social Mobility, U. Pompeu Fabra, may 19-20, 2010. We are grateful to our discussant Ghazala Azmat for her suggestions and to Daniel Parent for useful comments on a preliminary version of the paper. The first two authors gratefully acknowledge financial support from the Spanish Ministry of Education (ECO2009-10818; SEJ200763098), MCINN (Consolider- Ingenio2010) and Consejería de Educación de la Comunidad de Madrid (Excelecon project) .
}

Corresponding author: Sara de la Rica (ara.delarica@ehu.es). 


\section{Introduction}

One of the cornerstones of the standard competitive model of the labour market is the well-known equilibrium condition equating wage to marginal revenue product (MRP henceforth). Accordingly, the final wage distribution represents the equilibrium outcome of demand and supply forces. This straightforward implication of the competitive model has proven instrumental in the empirical analysis of how relevant phenomena, such as changes in the relative demand and supply of skills, have affected within and between-group wage inequality over the last few decades in economies with flexible labour markets, like e.g., UK and US (see, eg., Katz and Murphy, 1992). Yet, it is also well established that the competitive model can provide a rather misleading interpretation of how wages are actually determined in real-life labour markets when information is asymmetric or search frictions are present in the allocation of workers to jobs. In addition, a common feature of many existing labour market institutions (like unions and minimum wages) is that they tend to compress the wage distribution and thus reduce pay differences between more productive and less productive workers. ${ }^{1}$

While it is reasonable to acknowledge that the competitive paradigm often lacks realism in describing how wages are set, there are some specific forms of wage compensation that could be considered as good proxies of the "wage equals MRP" condition. In particular, if compensation is paid at least partially as a function of performance pay - such as bonuses, comission or piece rates- it seems plausible to assume that this wage component becomes closer to worker's productivity than the remaining components (e.g.,the base wage) that do not depend so closely on individual performance. Following this intuitive reasoning, Lemieux et al. (2009) have analyzed the impact of performance pay (PP hereafter) on wage inequality in the US. Their basic hypothesis is that, through a widespread reduction in the cost of gathering and processing information, growing incidence of PP may have contributed to the increase in inequality, mainly at the top of the wage distribution. Indeed, their finding that PP

\footnotetext{
${ }^{1}$ Empirical evidence, such as Beaudry and DiNardo (1991), Card (1996), DiNardo et al. (1996), Farber and Gibbons (1996), and Lemieux (1998) provide ample evidence about the different channels through which wages are not equalized to their MRPs.
} 
accounts for $25 \%$ of male wage inequality between the late 1970 s and early 1980 s provides favourable support for this conjecture. ${ }^{2}$

In this paper, we contribute to this line of research by making use of a recently available dataset on the detailed breakdown of total wage compensation for Spanish workers into its different components. We re-examine Lemieux et al. 's (2009) hypothesis, but from a different angle which, to our knowledge, is somewhat novel in this literature. ${ }^{3}$ Specifically, we analyze whether PP compensation differs by gender and the extent to which this component contributes to explaining the overall wage gender gap (gender gap hereafter) in Spain.

One could think of two alternative hypotheses regarding gender differences in PP. On the one hand, under the presumption that it is determined in a more competitive fashion than the remaining components of the wage, the gender gap in PP between equally skilled men and women could be smaller than in the non PP components. In other words, since in theory PP responds mostly to meritocracy, equally performing workers should receive the same PP irrespectively of their gender. Moreover, if women perceive some forms of (taste and/or statistical) discrimination in non-PP jobs relative to men, then they will seek intensively for PP in order to ameliorate these disadvantages. However, against this hypothesis one could claim that, to the extent that effort at the marketplace may be negatively affected by housework, PP could also provide a clear channel through which women's greater involvement in household tasks hinders their returns in the labour market and therefore lower their PP relative to men 's. ${ }^{4}$ For example, Amuedo-Dorantes and de la Rica (2006) find that overtime pay in Spain, which can easily make up to 40 percent of men's wages, account for up to 80 percent of the aggregate gender gap due to women 's lower availability to undertake long working hours.

\footnotetext{
2 The existing literature has mainly focused on analyses of the incentive effects on productivity of PP arrangements; see, inter alia, Booth (1999), Ewing (1996), Dohmen and Falk (2009) and Lazear (2000), among others.

${ }^{3}$ There is however a growing literature on gender differences in compensation for CEOs and top executives which shares element in common with performance pay (see, e.g., Bertrand and Hallock, 2001, and Bertrand et al., 2009)

${ }^{4}$ See Becker (1985) and a stylized model with this flavour in Appendix 2 (A).
} 
On the other hand, even abstracting from the role of distorting labour market institutions, the assumptions of free access to PP compensation and/or the absence of search frictions in a competitive setup may not be suitable for female workers. First, as stressed in the occupational segregation literature, women may select themselves into jobs where PP is either absent or scarce (e.g. public sector jobs) because they anticipate that these positions are more compatible with their larger household responsibilities. Hence, in line with the so-called mommy track hypothesis (see Mincer and Polacheck, 1977), they may willingly opt for jobs entailing steadier and, possibly, lower pay in exchange for less penalties in case of career interruptions. Secondly, employers may be more reluctant to place women in fast-track jobs, likely to involve PP, if they expect lower female work attachment even if they have the same ability distribution as their male colleagues (see Lazear and Rosen, 1990). Thirdly, statistical discrimination in the allocation of PP jobs may still prevail if employers invest on workers' specific training and therefore try to minimize quits. Moreover, if women are aware of the existence of statistical discrimination in advance, this may discourage them from applying to these jobs, leading to self-fulfilling equilibria (see Coate and Loury, 1993, and de la Rica et al., 2009). Lastly, the presence of some monopsonistic features in PP jobs, due to women's lower mobility or lack of alternative job offers, should not be discarded even if, contrary to the standard human capital explanation, this does not lead to lower productivity (see Booth et al., 2003, and Manning, 2003).

In view of these considerations, our goal in this paper is to dig deeper into the specific role played by PP as a determinant of the overall gender gap in Spain. Our data comes from the recently released 2006 wave of the Spanish Earnings Structure Survey which contains detailed micro-data information on the various components of the wage, such as the base wage, overtime pay and other wage complements. When compared to the longitudinal dataset used by Lemieux et al. (2009) - i.e., the interview years 1976-1999 of the PSID- our data suffers from a clear drawback since its crosssection nature prevents us from controlling for workers' fixed effects. In exchange, however, it has the advantage of providing information about the precise amount of PP received by workers, in contrast to PSID which only reports qualitative information on whether employees receive PP (but not its amount) as part of their total compensation, 
at least once during their employment relationships. This implies that our data are less noisy than theirs and that we can focus specifically on the PP component rather than on jobs that pay PP, as Lemieux et al. (2009) do.

In the first half of the paper, we address the impact of PP on the observed gender gap in total pay, both at the mean and throughout the wage distribution, since PP is bound to have substantially different effects at different percentiles. In effect, if PP is more concentrated at the higher quantiles, where bonuses and commissions are believed to represent a more important fraction of compensation, they may have a larger impact on the gender gap and therefore help explain at least partly the so-called "glass ceiling" effect at the top of the wage distribution. The second part focuses exclusively on the PP wage component and explores whether there are potential selection issues in the fraction of employees receiving PP, and to what extent the pattern observed for raw gender gaps changes once observable individual controls and selectivity biases are accounted for. Additionally, we present evidence about adjusted gender PP gaps within-firms and within-occupations in order to disentangle the role played by different theories explaining the existence of sizeable adjusted gaps.

The rest of the paper is organized as follows. Section 2 describes the dataset and provides some basic descriptive statistics regarding the whole sample, the distribution and extent of PP, the differences between the characteristics of workers receiving and not receiving $\mathrm{PP}$, and the contribution of the gender gap in $\mathrm{PP}$ to the overall gender gap in raw terms. In Section 3, we test whether the PP wage component is set in a more competitive way than the non-PP component. Section 4 deals with adjusted gaps in PP jobs. After addressing the issue of nonrandom selection among workers participating in PP jobs, we analyze which of the different explanations for gender gaps fits better with the evidence. Section 5 allows for different returns on observable characteristics by gender in order to identify which specific traits are differently rewarded in the market place. Finally, Section 6 concludes. 


\section{Data and descriptive statistics}

Our data source is the third wave of the Spanish Earnings Structure Survey (Encuesta de Estructura Salarial or ESS 06 in short). ${ }^{5}$ The ESS is the outcome of a European Project aiming at the design of harmonized earnings databases for several European countries. The survey is based on two-stage random samples of workers from establishments in the manufacturing, construction and service industries. First, establishments are randomly selected from the Social Security General Register of Payments records, which are stratified by region and establishment size. In a second stage, samples of workers from each of the selected establishments are also randomly drawn. Overall, sample sizes are much larger than in any other Spanish related surveys (see below for details). Besides wage compensation, EES collects individual information on workers' demographics (such as age and educational attainment) and job characteristics (including industry, occupation, contract type, type of collective bargaining, establishment' s export activity, establishment size, and region).

The main advantages of EES 06 relative to its earlier waves are that: (i) establishments with less than 10 employees are included in this survey whereas only employees in larger establishments were previously interviewed; (ii) it includes a module where employers provide detailed information on the breakdown of the total annual wage compensation paid to their workers into fixed and variable components. This module allows us to identify PP, since data on annual bonuses and commissions related to productivity are specifically reported for each employee. One important shortcoming, however, is that, since the latter information is directly provided by employers rather than by workers and the structure of EES does not enable us to construct a matched employer-employee dataset, information on either workers' civil status, spouses' characteristics or the number and age of children in the households is not available.

More concretely, besides reporting total monthly gross wages and working hours, EES 06 does provide information on both the ordinary (base wage and other complements due to shifts, tenure, job risks, etc.) and non-ordinary components of

\footnotetext{
${ }^{5}$ The previous waves correspond to 1995 and 2002.
} 
annual gross earnings. Regarding the latter category, the ESS 06 distinguishes between two different types of payments:

- Fixed Annual Non-ordinary Payments. This payment "basically corresponds to extraordinary compensations at Christmas and summer vacations (in Spanish, known as pagas por navidad y verano) ${ }^{6}$, the standard rates for overtime work and participation in firms' normal profits". It is specifically stated that their amount is known in advance by the employee, typically established at the collective bargaining level, and that they do not depend on either workers' or firms' performance.

- Variable Annual Non-ordinary Payments. In contrast to the first category, these are "payments related to workers' or firms' performance whose amount is not established a priori since it depends on incentives, returns and extraordinary profits". It lumps together bonuses, compensations and piece rates.

Given this breakdown of total wage compensation, the PP component in the sequel will correspond to the Variable Annual Non-ordinary Payments whereas the nonPP components will be identified as the sum of the ordinary wage and the Fixed Annual Non-ordinary Payments.

\subsection{Description of the dataset}

Our sample consists of full-time workers aged 18-65 for whom the interview month (october) is an ordinary period regarding their labour status. Table 1 displays the weighted descriptive statistics for the male and female samples. They contain a total of 129,930 males (66.6\%) and 65,223 females (33.4\%) covering almost 18,000 establishments.

\section{[Table 1 about here]}

Inspection of workers' demographic characteristics reveals the following stylized facts: (i) women's educational attainments are significantly larger than men's

${ }^{6}$ This implies that the fixed part of the total annual gross wage is distributed into 12 ordinary instalments and 2 extraordinary ones. This tradition dates back to the Francoist industrial relations during the dictatorship period. 
- e.g., the percentage of female workers with a university degree (32\%) almost doubles men's $(18 \%)$ whereas the fraction of women with at most primary education is $10 \mathrm{pp}$. smaller (18\% vs. $28 \%$ ) than men's, (ii) women are about two years younger than men (from interpolation of the mid-points of the different age brackets), (iii) female job tenure is about 1.5 years shorter than males' tenure, and (iv) the raw gender gap is about $21 \log$ points in favour of male workers. As regards firms' characteristics, on average, women work in larger establishments (> 200 employees) than men (a 9 pp. higher share), and enjoy a lower coverage by bargaining agreements at the firm level (3 pp. less).

Regarding total gross hourly wages, the gender gap in favour of men is about 21 log points, using differences in mean logged wages, and $23.1 \%$, using the ratio of the wage levels. ${ }^{7}$ Interestingly, the incidence of PP $(22.7 \%)$ is almost identical across genders which, prima facie, is consistent with our previous conjecture that this kind of jobs are attractive to women because, in principle, they should be less subject to discriminatory practices. This statement, however, will need to be reconsidered later on, once we report further evidence on the distribution of women throughout the PP distribution.

\subsection{Characterization of performance pay}

Table 2a compares the sample characteristics of workers receiving PP and not receiving PP, distinguishing by gender, as well as of the firms where they work. The main finding is that workers receiving PP are more educated than the others $(40 \%$ of women and $27 \%$ of men in the PP sample have a university degree against $29 \%$ and $15 \%$ in the non-PP sample). Likewise, they are older (about a $10 \mathrm{pp}$. larger share in the 31-50 age range), have longer tenure (about 2.5 years longer for women and 5 years for men), enjoy a higher rate of permanent contracts and work in larger establishments (typically less subject to centralized bargaining levels).

7 Denoting the total annual gross wage by GAW, total hourly wages are defined as $w=$ GAW /ORH+OVH), where ORH represents annual ordinary working hours set at the collective bargaining agreement (jornada anual pactada) and $\mathrm{OVH}$ denotes the overtime working hours completed in the month of the interview (october). The latter are annualized using the seasonal pattern of aggregate extra hours in the Spanish economy as of 2006. 
Table $2 b$, in turn, presents the incidence of PP by industry and occupation. Regarding industries, Financial Intermediation (60\%) and Education (9\%) are the sectors where PP is most and least prevalent, respectively. As for occupations, the results confirm that PP incidence is much higher among the high-wage categories: 50\% for Managers and 30\% for Professionals and Technicians.

Finally, Table $2 \mathrm{c}$ reports the share of female workers receiving PP throughout the distribution of this component of the wage, which we can compare to the average share of women receiving PP in our sample, i.e., about 35\% (=14798/44249). The sharp decline in this proportion as we move upward in the PP distribution - from $41 \%$ at the bottom to $16 \%$ at the top- is seemingly inconsistent with the above-mentioned conjecture about more skilled women being more likely to seek jobs entailing PP compensation, especially since, as reported above, they have higher educational attainments than men. By contrast, such evidence would be consistent with the implications of theories based on occupational segregation and/or lower mobility which predict a "glass "ceiling "pattern whereby well qualified females are less likely to get better paid positions than high qualified males.

\section{[Tables $2 a, b$ and $c$ about here]}

\subsection{The Contribution of Performance Pay to the Overall Gender Gap}

We next analyze how important is PP, the size of the gender gap in this wage component and, finally, its contribution to the overall gender gap. As explained in Appendix 1, the computation of the respective contributions of the gender gaps in the $\mathrm{PP}$ and non-PP components to the overall gender gap is greatly facilitated by using a measure of the gap expressed in percent (i.e., the ratio between average male and female wage minus unity) rather than in log points (differences in average logged wages), as is customary in the literature. The first four columns in Table 3a present the total hourly wage compensation in PP (expressed in $€$ ) across genders and the corresponding shares of total wages accounted by the PP component. Further, for comparison, the hourly wages of non-PP workers appear in the last two columns. Table $3 \mathrm{~b}$ reports similar evidence but this time referred to the two components of the wage 
compensation received by PP workers, i.e. its variable and non-variable components. Lastly, Figure 1 plots the three gender gaps in percentage terms (total hourly wage, $w$, $\mathrm{PP} /$ variable component, $v$, and other/fixed or predetermined components, $f$ ) both at the mean and throughout the wage distribution for the whole sample of workers in our sample.

As can be observed, workers with PP earn more on average than non-PP workers (about $64 \%$ and 50\% higher wages for men and women, respectively) in line with the evidence offered in Table 2a about the higher skills and longer job tenure of the former. Using individual information on the PP component of the wage, we can compute its unadjusted/raw gender gap. This yields a strikingly large gap of 74\% (around 46 log points using the conventional measure of the gap based on the geometric mean) in favour of men. This gap turns out to be much larger than the raw gap in total hourly wages found for the whole sample ( $24 \%$ or 20.6 log-points). However, the share of the PP component in the total wage is rather low: 7.2\% for women and $9 \%$ for men on average. Nonetheless, as expected, the PP share increases over the wage distribution, reaching $22 \%$ (men) and $17 \%$ (women) at the $90^{\text {th }}$ percentile (P90th). Taken together, the low average PP share and the low incidence of workers with PP in our sample (22.7\%) imply a rather tiny contribution of the gap in PP to the overall gender gap for the whole sample of workers: 1.7 pp. out of 24.0 pp. (about 7\%), despite exhibiting a mild increase at the upper part of the wage distribution where it reaches 3.8 pp. out of 33 pp. (11.5\%) at P90th.

\section{[Tables $3 a$ and $b$ about here]}

\section{[Figure 1 about here]}

The next step is to examine whether PP plays a more relevant role when we consider the sample of workers with PP exclusively. Using this restricted sample, Figure 2 displays the raw gaps, again both at the mean and throughout the distribution, in the total hourly wage $(w)$, the non-PP/fixed component $(f)$ together with the estimated contribution of the PP component to the overall gap as explained in Appendix $1 .{ }^{8}$ As expected, the contribution of PP to the aggregate hourly wage gap is now higher than in

\footnotetext{
${ }^{8}$ The gap in the PP component $(v)$ is the one displayed in Figure 1.
} 
the whole sample reaching, on average, 5.7 pp. out of 32 pp. (i.e., about $18 \%$ ) and 11.7 pp. out of 46.5 pp. (25\%) at the top of the distribution.

In sum, two main conclusions stem from this preliminary evidence: (I) the gender gap in PP is much larger than in total hourly wage compensation, particularly at the top of the wage distribution where it can explain about one-fourth of the "glass ceiling" pattern observed at the higher percentiles, and (II) PP makes a dent at higher wages in line with the previous evidence that workers receiving this type of variable compensation have better observable characteristics.

In principle, several theories would be consistent with the above-mentioned results. First, as regards finding (I), it is likely that wages set in collective bargaining at the sectoral (provincial-, industry-wide) level and actual wages are similar for noncollege workers in less-skilled/blue-collar occupations, while bargained wages do not bind for college workers in high skill/ white collar occupations. There is evidence (see Dolado et al., 1997) pointing out that employers in Spain improve high-skill workers' pay above compressed bargained wages through formal and informal agreements which are likely to involve variable PP arrangements. Therefore, insofar as unions compress the wage distribution and base wages respond more to occupational categories and tenure than to individual characteristics, like gender, it is likely that the raw non-PP gender gap would be quite smaller than the raw PP gap. This is confirmed by the fact that the standard deviation of the (logged) fixed component of total hourly wages (0.61 and 0.60 for men and women, respectively) is less than one-half the standard deviation of the (logged) PP component (1.41 and 1.34, respectively).

As for finding (II), it could be rationalized by either: (i) women with PP exerting less effort than men due to disutility of housework, (ii) women self-selecting away from jobs where PP represents a relevantshare of total compensation, or (iii) women receiving lower PP than men due to monopsonistic features elements in the PP segment of the labour market, possibly related to employers' beliefs that women enjoy lower mobility than equally qualified men.

Appendix 2 (A andB) presents simple models which illustrates the main gender implications of jobs offering PP in competitive (A) and non-competitive (B) frameworks 
to server as background for the discussion of the main predictions of the abovementioned theories discussed throghout the sequel.

Disentangling which of the previous theories is more likely to operate in explaining the very large gender gap found for PP requires several steps. First, Lemieux et al.'s (2009) hypothesis that PP tends to be closer to MRP than non-PP compensation ought to be tested in our sample. Next, we also need to examine whether the pattern of the PP raw gap discussed above remains similar once it is adjusted for differences in individual and job characteristics across genders. In other words, it is only under the competitive labor market paradigm and under similar observable characteristics that the documented PP gap can be described as being "strikingly large". The next two sections are devoted to address these issues.

\section{[Figure 2 about here]}

\section{Is PP determined in a competitive fashion?}

Following the above-mentioned motivation, we devote this section to analyze whether PP is "more attached to the worker" whereas non-PP compensation is more "attached to the job". Once more, the basic insight is that, if PP depends essentially on individuals' endowed and acquired characteristics, MRP would be more transferable across firms and occupations, and hence human capital variables - basically age, education and, to a lesser extent, tenure ${ }^{9}$-should have higher market returns than for workers not receiving PP. Conversely, returns to job characteristics- such as firm size, sector, and tenure on the firm should receive a higher market reward for the latter.

To analyze this issue, Table 4 reports standard mincerian (logged) hourly wage regressions estimated by OLS where the returns (estimated coefficients) to job and human capital variables are displayed separately in the first two columns for workers with and without PP, respectively. The third column, in turn, shows the results from a pooled regression where interactions of human capital and job characteristics with an indicator of receiving $\mathrm{PP}$ are added to test for statistically significant differences

\footnotetext{
${ }^{9}$ The lower (in absolute terms) coefficient on the interaction of tenure and the PP indicator may reflect high union power in collective bargaining determining the non-PP components of the wage, where tenure is a key element in wage increases.
} 
between returns in the two samples. Thus, denoting the hourly wage of worker $i$ in firm $j$ as $W_{i j}$, individual and job characteristics as $X_{i}$ and $X_{j}$, respectively, and an indicator (1/0) for receiving PP as $D_{i}$, the estimated model is:

$$
\ln W_{i j}=\beta_{0}+\beta_{1} D_{i}+X_{i} \beta_{2}+X_{j} \beta_{3}+D_{i} X_{i} \phi_{1}+D_{i} X_{j} \phi_{2}+\varepsilon_{i j}
$$

where we expect $\phi_{1}>0$ and $\phi_{2}<0$.

In line with the results by Lemieux et al. (2009), we find that the returns to characteristics attached to the worker are larger for workers with PP than for non-PP workers. For example, the returns to university and secondary education are $41 \%$ (0.304 vs. 0.215$)$ and $60 \%$ (0.09 vs. 0.06) larger, respectively, than for non-PP workers. Likewise, the returns to age, as a proxy for potential experience, and to a lesser extent tenure follow the same pattern. By contrast, the returns to firm size and other characteristics of the job are significantly smaller for workers with PP, as it is also the case for estimated coefficients on industry and occupational dummies, not reported in this table for brevity. This evidence suports the view that PP responds more to worker 's productivity than the rest. Yet, the fact thatestimated returns on firm's characteristics are, in gereneral, statistically significant points out that workers tend to be categorized by firms into jobs, albeit less so in the sample of workers receiving PP.

\section{[Table 4 about here]}

\section{Adjusted gender gaps in the performance pay component}

Once the pattern of the raw gender gap in PP has been described, we next proceed to compute their adjusted counterparts, accounting for differences in observed individual and job characteristics. However, the fact that slightly less than one-fourth of workers in the whole sample receive PP and that they present different personal and job characteristics than non-PP workers, make us consider that non random selection of workers into the sample of those with PP may be a relevant issue to address. This is particularly important if the selection process into PP is not exactly the same for males and females In such a case, ignoring gender differences in selection could lead to biased estimates of the adjusted gap for the PP component. 


\subsection{Selectivity issues}

Table 5 presents the results of estimating a probit model to explain participation in $\mathrm{PP}$ jobs $(\mathrm{PP}=1$, non- $\mathrm{PP}=0)$. This model will be later used to compute the inverse Mill ratio in a conventional two-stage Heckman approach to control for selection in the estimation of log hourly wage regressions explaining the PP component. Given the lack of information regarding civil status or number and age of children in our sample, we use the availability of wage bargaining at the firm level (Firm Agreement) as the identifying variable in the participation equation. The insight for this choice is that workers subject to this type of decentralized wage-setting agreement are more likely to receive PP compensation than those whose wages are set at a more centralized bargaining level (sectoral/provincial or nationwide) where unions play a larger role. Further, the fact that the estimated coefficient on this variable is not statistically significant when included in the PP wage regression make us rely upon the validity of this exclusion restriction.

The first column of Table 5 presents the estimates of the coefficients in the probit using the standard explanatory variables, where a Female indicator $(1 / 0)$ captures gender differences in the probability of receiving PP compensation. As can be observed, women have a lower probability of receiving PP than equally able men working in the same occupations. The remaining estimates are in line with the evidence presented in Table 2: higher educational attainment, longer tenure and being in the 31-50 age intervals also raise this probability.

Thus, in principle, this evidence goes against the earlier conjecture that, under the competitive labour market paradigm, equally productive men and women should not exhibit significant differences regarding paticipation in jobs offering PP compensation and that, if females anticipate non-competitive features in jobs that do not entail PP, they are likely to be more prevalent in those paying PP. To examine whether these differences in participation can be related to women's larger disutility in market work due to larger involvement in housework, as in Becker's hypothesis, or rather to occupational segregation and/or lower mobility, as in the " mommy track" and "monopsonistic" hypotheses, the second column in Table 5 reports the estimates 
obtained from a regression where interaction terms between the different age brackets and the Female dummy are added to the model. Under the first hypothesis, the main differences againt women shoud appear for those age groups more prone to bear household responsibilities since it is actual involvement in housework that hampers performance in market work. Lacking information on civil status and household composition, we choose to identify women aged $31-50$ as those more prone to be heavily involved in child bearing, looking after elderly relatives, etc. Thus, conditioning on the remaining observable controls, one should expect lower probability of participation for women in this age group. This would correspond to a negative coefficient on the corresponding interaction terms between PP and the 31-39 and 40-49 age-bracket indicators. By contrast, under the second hypothesis, the effect should be mainly captured by the female intercept since all women, irrespectively of their age, antipate career interruptions due to the above-mentioned reasons.

The basic finding is that the coefficients on these interaction terms are negative and highly significant, pointing out that, conditioning on all the remaining covariates, women in two above-mentioned age brackets have a lower probability of receiving PP than younger and older women, respectively. For example, the net coefficient of a woman aged 30-39 is $-0.134(=-0.103+0.016-0.047)$ whereas, for women below 30 or in the 50-59 interval, the corresponding net coefficients would be -0.103 and $-0.041(=-$ 0.103-0.01+0.072), respectively. A chi-squared test rejects the null of equal coefficients across the previous age brackets with a p-value of 0.023 . Thus, this evidence points out the "mommy track" / monopsonistic" hypotheses are likely to play a joint role in explaning gender differences in receiving PP.

\section{[Table 5 about here]}

\subsection{Disentangling occupational segregation from monopsonistic features}

\subsubsection{Within- firms and within- occupations regressions}

The next step is to analyze which of the two theories embedded in the second joint hypothesis is more likely to explain the PP gender gap: is it "occupational segregation" or "monopsonistic features" ?. To try to discriminate between these two somewhat alternative explanations, we carry out the following exercise. Using the specification of 
a mincerian log wage equation for the restricted sample of PP workers with a Female intercept and equal returns to individual and job characteristics across genders, we compare the estimated coefficient on the Female indicator in a regression (augmented by the inverse Mills ratio obtained from the participation equation reported in the second column of Table 5) under four different specifications: (i) a pooled regression $(P)$, (ii) within- occupations $(W O),{ }^{10}$ (iii) within-firms (WF), and (iv) within-firms \& occupations (WFO).

The insight for such comparison can be briefly described as follows. Let us denote the coefficient on the Female dummy in the four specifications above as $\beta_{P}, \beta_{W O}, \beta_{W F}$ and $\beta_{W F O}$ respectively. Then, under the "occupational segregation "hypothesis we should expect $\beta_{w O}$ to be significantly smaller than $\beta_{p}$ (since we are comparing men and women in the same occupation and firm) whereas $\beta_{W F}$ should be similar to $\beta_{P}$. Conversely, under the "monopsonistic" hypothesis, the estimate of $\beta_{W F}$ should be quite smaller than the estimate of $\beta_{p}$ (since now the comparison is between men and women working in the same firm), while $\beta_{W O}$ and $\beta_{P}$ would be similar. Finally, if both theories play a role, then $\beta_{W F O}$ should be below both $\beta_{W O}$ and $\beta_{W F}$ which, in turn, should be smaller than $\beta_{P}$.

Table 6 reports the estimates obtained under the alternative specifications where the OLS results (without selection correction) are also included in the first column for comparison. The following findings stand out. First, the adjusted average gender gap in the OLS pooled specification is about 41 log points against a raw gap of 46 log points. Second, once we control for selection bias in such specification, the gap increases slightly to $45 \log$ points. The fact that this gap is larger than the OLS gap is explained by the highly significant positive sign on the coefficient of Heckman's lambda which reflects strongly positive selection of workers receiving PP. Since women have higher educational attainment than men in our sample, despite having lower tenure, this leads to a larger gap when selection is taken into account. Third, again controlling for selection biases, the estimate of the gap in the within-firm specification (34 log points) is

\footnotetext{
${ }^{10}$ We use the most disaggregated occupational classification available for our dataset, namely, 18 occupational categories
} 
quite smaller than the corresponding estimate in the within-occupation specification (43 log-points) which, in turn, is quite close to the gap estimated in the pooled specification (41 log points). Finally, the gap in the joint within-firm and occupation (29 log-points) is slightly lower than the gap in the within-firm and within-occupation model. Overall, we interpret this evidence as seemingly yielding higher support to the "monopsonistic" hypothesis at the joint occupational-firm level than to the conventional "occupational segregation" hypothesis in explaining the large PP gender gap.

\section{[Table 6 about here]}

Nonetheless, the previous conclusion could be premature if it were to be the case that women exert less effort than men in the same occupation and firm because of their larger involvement in housework. In such a case, differences in effort could also be behind the gap in PP. Lacking a precise measure of productivity, it is difficult to test this hypothesis. However, despite the absence of controls on household composition, the fact that our sample consist of full-time workers and that we control for age, education and tenure - all related to productivity- as well as that the overtime hours are similar for men and women, make us believe that gender differences in effort do not play an important role in explaining the gap in PP. One possible test of differences in effort can be implemented by checking whether the proportion that PP represents over the total hourly wage is lower for women than for men, once we control for differences in characteristics and sample selection. The insight for such a test is simply that higher effort should give rise to a larger proportion of PP. As mentioned above, on average, these proportions are $9 \%$ for men and $7.2 \%$ for women. Though not reported for brevity, we have estimated a similar mincerian regression to that shown in column (5) of Table 6, where the dependent variable is the logit transformation of the abovementioned proportion. ${ }^{11}$ We obtain that the Female indicator explains less than one half (0.85 pp.) of the 1.8 p.p. gap (=9.0-7.2) gap in the proportions. Therefore, we conclude

11 The logit transformation, $\ln (R / 1-R) \in(-\infty,+\infty)$, achieves consistency with the support of the distribution of the error tem in the regression, where $R \in(0,1)$ is the proportion of $\mathrm{PP}$ in the total hourly wage. Denoting by $b$ the estimated coefficient in the regression, then the effect of the Female dummy, $D$, on $R$ becomes $\delta R / \delta D=b R(1-R)$. 
that such a difference is too small to be considered as a very relevant factor in explaining the gender gap in PP.

\subsubsection{Quantile regressions}

Further evidence on this issue can be obtained from comparing the relative pattern of the gender gap throughout the distribution on the PP component. Indeed the available theories on female segregation in slow-track jobs (aka non-PP jobs in our setup), like Lazear and Rosen 's (1993), predict that gender gaps arise because women face lower probability of being assigned to jobs entailing PP jobs even if they are as skilled as men, not because they are subject to within-job discrimination. However, given that the ability standard for allocation to jobs where PP is paid is higher for women, it should be expected that the relatively few women who are at the top of the PP distribution should receive higher PP compensation than their male counterparts (see Appendix 2). In other words, conditioning on observable characteristics, the gender gap should be negative at the top percentiles of the PP distribution. By contrast, theories related to lower female mobility, like Booth et al. 's (2003) "sticky floors" hypothesis, predict that women at all percentiles will be paid less than men since there is a higher rent to be earned by firms due to women having lower outside opportunities because employers perceive that they are less mobile than men.

To test which of the two previous implications is supported by the data, we use quantile regressions $(\mathrm{QR})$ accounting for selectivity corrections under the within-firm \& occupation specification. Following Buchinsky's (1998) approach, the selectivity correction for workers receiving PP is based on a two-stage approach. First, a two-term series expansion of the inverse of the Mills ratio in Table 5 is used to obtain an estimate of a latent index that approximates the unknown quantile functions of the truncated bivariate distribution for the error terms in the wage and participation equations. Then, the covariance matrix for the two-stage QR and the selectivity corrected estimates is obtained by bootstrapping the design matrix with 100 replications.

Table 7 reports the QR estimates of the coefficient on the Female indicator for a few relevant percentiles of the PP distribution. A clear "glass ceiling" pattern emerges with the gap evolving from 20 log-points at the bottom deciles to 43 log points at the top of 
the distribution. In line with our previous discussion, we interpret this evidence as yielding higher support to the existence of monopsonistic features in the determination of PP than to female occupational segregation.

\section{[Table 7 about here]}

\section{Decomposing the Gender Gap in PP}

So far, the estimated models have assumed the same market returns (coefficients) to male and female characteristics, except the intercept. Since this assumption is rejected by the data $(p$-value $=0.023)$, we next report results allowing for different remuneration to observed characteristics for workers receiving PP.

Table 8 summarises the results of the slightly modified version of the Oaxaca-Blinder gender gap decomposition proposed by Gardeazabal and Ugidos (2004) when, as in our case, there are indicator variables in the hourly wage regressions which can take more than two categories (e.g., education and age). The reported results correspond to the WFO specification. In general, we find that the contribution of differences in returns to explain the PP gap (46 log-points) is much larger $(88 \%)$ than the contribution of differences in characteristics (12\%). Among the former, the largest components are the differences in constant terms (26 log points) and in the returns to age. Though we only report the aggregate contribution for all age categories, it is worth noticing that the two specific categories where differences in returns are larger are the 30-39 and 40-49 age groups which jointly account for 5.67 log-points out of the $8.46 \mathrm{log}$ - points contributed by age. This result somewhat points out that typical ages where individuals incur in child bearing or other household tasks involves a "marriage premium " for males and a "child/elderly parent penalty" for women, in line with many studies of the gender gap in Spain (see, e.g., de la Rica et al. , 2008). Interestingly, albeit not large, the differences in returns to tenure favour women, in agreement with our previous result that firms may find it optimal to offer steeper wage-tenure profiles to women than to men in order to retain them (see Appendix 2). Finally, the fact that the female intercept accounts for $26 \mathrm{log}$ points of the overall gender gap when in the pooled WFO regression it accounted for 29 log-points may just reflect that the lack of variables in our dataset capturing civil status and household composition may still biasing upwards the size of this coefficient. 
All in all, the result in this section do not change our previous conjecture that the gender gap in PP and the corresponding "glass ceiling" may be well due to monopsonistic features in PP jobs, whereby female lower mobility leads to a rate of exploitation by firms even when women acquire higher education than men to signal their commitment to job stability.

\section{Concluding remarks}

In this paper we have used a large cross-section dataset for Spanish workers in 2006 to examine whether the gender performance-pay (PP) gap differs from the gender gaps in other components of wage compensation. We have found evidence that PP responds more to workers' performance and that women receiving PP have several observable characteristics which are better than men's (e.g., educational attainment). Yet, our main result is that the gender gap in PP is much higher, both in raw terms and adjusted for observable characteristics, than the gap in non-PP compensation, and that there are clear signs of a "glass ceiling" effect (higher gaps and lower female participation of women in the upper parts of the PP distribution). Our explanation for these findings relies mostly on the existence of monopsonistic features in the PP segment of the labour market, possibly related to women's lower mobility due to their attachment to household tasks, and to a lesser extent on theories explaining women 's segregation in different occupations than men. Nonetheless, this interpretation has to be taken with a caution since our dataset lacks information on workers' civil status and household composition which can only be (rather imperfectly) proxied by workers' age groups. 


\section{References}

Amuedo-Dorantes, C. \& S. de la Rica (2006), "The Role of Segregation and Pay Structure on the Gender Wage Gap: Evidence from Matched Employer-Employee Data for Spain", Contributions to Economic Analysis and Policies, Berkeley Electronic Press Journals, 1.

Beaudry, Paul \& J. DiNardo (1991), "The effect of implicit contracts on the movement of wages over the business cycle: Evidence from Micro Data", Journal of Political Economy, 99(4):665-688

Becker, G. (1985), "Human Capital, Effort and the Sexual Division of Labor", Journal of Labor Economics, 3.

Bertrand, M. \& K. Hallock (2001), "The Gender Gap in Top Corporate Jobs", Industrial and Labor Relations Review,55, 3-21.

Bertrand,M., Goldin, G. \& L. F. Katz (2009), “ Dynamics of the gender gap for young professionals in the corporate and financial sectors" NBER W.P. Series 14681.

Booth, A. \& J. Frank (1999), "Earnings, Productivity and Performance-Pay", Journal of Labor Economics, 17 (3).

Booth, A., Francesconi, M \& J. Frank (2003), “A sticky floors model of promotion, pay and gender", European Economic Review, 47, 295-322.

Buchinsky, M.(1998), "Recent Advances in Quantile Regression Models: A Practical Guideline for Empirical Research." Journal of Human Resources , 33.

Card, D. (1996), "The Effect of Unions on the Structure of Wages: A Longitudinal Analysis." Econometrica 64.

Coate, S. \& G. Loury (1993), "Will affirmative-action policies eliminate negative stereotypes ", American Economic Review, 83, 1220-40.

de la Rica, S., Dolado, J.J. \& V. Llorens (2008), "Ceilings or floors ?. Gender wage gaps by education in Spain", Journal of Population Economics, 21, 755-776.

de la Rica, S., Dolado, J.J. \& C. García-Peñalosa (2009), "On gender gaps and self-fulfilling expectations: Theory, policies and some empirical evidence", IZA Discussion Paper No. 3553.

DiNardo, J., Fortin, N \& T. Lemieux (1996), "Labor Market Institutions and the Distribution of Wages, 1973-1992: A Semiparametric Approach," Econometrica, 64(5), 1001-44.

Dolado, J.J. , J. Jimeno \& F. Felgueroso (1997), "Minimum Wages, Collective Bargaining and Wage Dispersion: The Spanish Case" European Economic Review, 41, 713-725 .

Dohmen, T. \& A. Falk (2009), “Performance Pay and Multi-dimensional Sorting Productivity, Preferences and Gender", Forthcoming in American Economic Review.

Ewing, B. (1996), "Wages and performance-based pay: Evidence from NLSY”, Economic Letters 51, 241-246.

Farber, H. \& R. Gibbons (1996), “Learning and Wage Dynamics”, The Quarterly Journal of Economics . 
Gardeázabal, J \& A. Ugidos (2004) “ More on identification in detailed wage decompositions", Review of Economics and Statistics, 86, 1034-36.

Katz, L.F. \& K.M. Murphy (1992), “Changes in relative wages, 1963-1987: Supply and demand factors" Quarterly Journal of Economics, 107, 35-78.

Lazear, E. \& S. Rosen (1990), "Male and female differentials in job ladders", Journal of Labor Economics, 8, 106-123.

Lazear, E. (2000): “Performance Pay and Productivity," American Economic Review, 90(5), 1346-1362.

Lemieux, T. (1998), "Estimating the Effects of Unions on Wage Inequality in a Panel Data Model with Comparative Advantage and Non-Random Selection" Journal of Labor Economics 16, April 1998, pp. 261-291

Lemieux, T. \& D. Parent (2009), "Performance Pay and Wage Inequality”, Quarterly Journal of Economics 124(1), 1-49.

Manning, A. (2003), Monopsony in motion: Imperfect competition in Labor Markets, Princeton University Press.

Mincer, J. \& S. Polacheck, 1977, “Women's earnings re-examined”, The Journal of Human Resources, 13 (1). 


\section{APPENDIX 1: Contribution of PP gender gap to the total gender gap}

The total hourly wage $(w)$ is defined as the sum of the non-PP/fixed component $(f)$ and the $\mathrm{PP} /$ variable component $(v)$. Since $\ln (f+v) \neq \ln (f)+\ln (v)$, it is difficult to compute the gender gap in log points (as is customary in the literature) by means of the difference between the averages of logged wages for males $(M)$ as females $(F)$ i.e., as $\overline{\ln }_{M}-\overline{\ln }_{F}$, and then proceed to decompose the overall gap into the respective gaps of the fixed and variable components.

However, such decomposition is straightforward if we express the gaps in percent rather than in logged points. In effect, given that:

$$
w=f+v
$$

then taking sample averages for each gender yields:

$$
\begin{aligned}
& \bar{w}_{M}=\bar{f}_{M}+\bar{v}_{M} \\
& \bar{w}_{F}=\bar{f}_{F}+\bar{v}_{F}
\end{aligned}
$$

Therefore, the following decomposition of the total gender gap (in percent) in terms of the two gender gaps in the components (also in percent) holds exactly for the restricted sample of workers receiving PP:

$$
\left(\frac{\bar{w}_{M}-\bar{w}_{F}}{\bar{w}_{F}}\right)_{P P}=\alpha\left(\frac{\bar{f}_{M}-\bar{f}_{F}}{\bar{f}_{F}}\right)_{P P}+(1-\alpha)\left(\frac{\bar{v}_{M}-\bar{v}_{F}}{\bar{v}_{F}}\right)_{P P}
$$

where $\alpha=\frac{\bar{f}_{F}}{\bar{w}_{F}}$, while, for the whole sample of PP and non-PP workers, we have:

$$
\left(\frac{\bar{w}_{M}-\bar{w}_{F}}{\bar{w}_{F}}\right)_{A L L}=\alpha\left(\frac{\bar{f}_{M}-\bar{f}_{F}}{\bar{f}_{F}}\right)_{A L L}+(1-\alpha) \varphi\left(\frac{\bar{v}_{M}-\bar{v}_{F}}{\bar{v}_{F}}\right)_{P P}
$$

such that $\varphi=\frac{N_{P P}}{N_{A L L}}$, where $N_{P P}$ and $N_{A L L}$ are the respective number of observations in the restricted and whole samples. Hence, the second terms in the RHS of (A.1.3) and (A.1.4) are interpreted as the contributions of the gender gap in the PP component to the overall gender gap in the two samples. 


\section{APPENDIX 2: An illustrative model of the gender implications of PP}

\section{(A) Competitive wages}

Let us assume that a PP worker of (exogenous) skill $\delta$ receives a wage $W$ per unit of output produced and that firms incur a fixed $C$ of monitoring the worker which in a competitive market is paid by the worker. Denoting effort by $e$, output is assumed to be $(\delta+e)$. Effort produces a disutility cost $c(e)$ which is increasing and convex. We assume the functional form $c(e)=e^{1+\gamma} /(1+\gamma)$ with $\gamma>0$. Given women's higher involvement in housework, their disutility of effort is higher than for men, namely, $\phi e^{1+\gamma} /(1+\gamma)$, where $\phi>1$. Therefore, we can write down the utility of men (M) and women $(\mathrm{F})$ in PP jobs as follows:

$$
\begin{aligned}
& U_{M}^{P P}=W(\delta+e)-C-e^{1+\gamma} /(1+\gamma) \\
& U_{F}^{P P}=W(\delta+e)-C-\phi e^{1+\gamma} /(1+\gamma)
\end{aligned}
$$

Regarding non PP jobs, let us assume that the worker produces a minimum level of output, say $\bar{\delta}$, which can be monitored by the firm at no cost and does not involve any effort. After all, it is painful to produce output and, in the absence of monitoring, the worker can get away without producing any more than $\bar{\delta}$. This implies that the utility for both men and women of this type of job is simply given by:

$$
U^{N P P}=W \bar{\delta}
$$

Workers' effort decision in PP jobs is simply obtained by equating the marginal revenue from exerting effort to its marginal cost. From (A.2.1) and (A.2.2), it yields $W=e_{M}^{\gamma}$ and $W_{F}=\phi e_{F}^{\gamma}$, whereby $e_{M}^{\gamma}=\phi e_{F}^{\gamma}>e_{F}^{\gamma}$. Substituting these two expression into (A.2.1) and (A.2.2), implies that worker $i(=M, F)$ will choose PP for $\delta>\delta_{i}^{*}$, where

$$
\begin{aligned}
& U_{M}^{P P}\left(\delta_{M}^{*}\right)=\frac{\gamma}{1+\gamma} e_{M}^{1+\gamma}+\delta_{M}^{*} e_{M}^{\gamma}=\frac{\gamma \phi}{1+\gamma} e_{F}^{1+\gamma}+\varphi \delta_{M}^{*} e_{F}^{\gamma}-C=W \bar{\delta}=U^{N P P} \\
& U_{F}^{P P}\left(\delta_{F}^{*}\right)=\frac{\gamma \phi}{1+\gamma} e_{F}^{1+\gamma}+\delta_{F}^{*} e_{F}^{\gamma}-C=W \bar{\delta}=U^{N P P}
\end{aligned}
$$

Comparing both expressions, we get that $\delta_{F}=\phi \delta_{M}>\delta_{M}$. Thus, assuming that the skills distribution is identical across genders, we should expect fewer women in PP jobs and, conditionally on receiving PP, higher ability among female workers than among male workers.

Further, if women are aware of discrimination in non- PP jobs where, say, they get paid $U_{F}^{N P P}=\alpha W \bar{\delta}$, with $0<\alpha<1$, whereas $U_{M}^{N P P}=W \bar{\delta}$, then obviously they will have higher preference for PP jobs than before. Moreover, in this case they will even be more prominent in PP jobs than men if $\phi=1$. 


\section{(B) Predetermined wages and job attachment uncertainty}

A slightly different model where wages are no longer given but set by employers in order to avoid career interruption can be written using a slight adaptation of Lazear and Rosen 's (1992) model of assignment of workers to slow and fast- jobs. Let us assume that individuals in PP jobs work for two periods and are endowed with the same ability $\delta$ which is known to the firm. In the initial period, they produce $\delta$ and receive a wage $W_{1}$. As a result of longer tenure, their productivity in period 2 raises to $\mu \delta$, where $\mu>1$ and get paid $W_{2}$. It is assumed that, workers receive a disutility shock, $\omega$, in both periods which may force them to quit the job (say, for family duties). The $\omega$ shock is an i.i.d. random variable, independent across periods, with c.d.f. $F(\omega)$ which is revealed to the worker after the wage in either period has been set by the firm. Thus, wages are predetermined and workers will stay in the firm both periods as long as $W_{t i}-\omega \geq 0, t=1,2$ and $i=F, M$.

The key difference between men and women is that the c.d.f. for men, $F_{M}(\omega)$, is stochastically dominated by the c.d.f. for women $F_{F}(\omega)$, namely $F_{M}(\omega)$ $>F_{F}(\omega)$ for $\omega>0$. This assumption captures the fact that women are more likely to be affected by the shock than men. To simplify matters, and without loss of generality in terms of the qualitative results, we will assume that $\mathrm{dF}($.$) are$ uniform distributions, such that the density functions verify: $f_{M}(\omega)=U\left[0, \varepsilon_{M}\right]$ and $\mathrm{f}_{\mathrm{F}}(\omega)=\mathrm{U}\left[0, \varepsilon_{\mathrm{F}}\right]$, with $\varepsilon_{\mathrm{F}}>\varepsilon_{\mathrm{M}}$.

To solve for both wages, we proceed backwards in time. Under the assumption that the wage in period $2, W_{2 i}(i=f, m)$, is offered before $\omega$ is realized, employers will choose $W_{2 i}$ in order to maximize expected profits in period 2 , subject to the participation constraint in this period and conditional on the probability of staying in the firm during period 1 (equal to $W_{1 i} / \varepsilon_{i}$ under a uniform distribution), namely:

$$
\max _{W_{2 i}} \frac{W_{1 i}}{\varepsilon_{i}} \int_{0}^{W_{2 i}}\left(\mu \delta-W_{2 i}\right) d \omega=\max _{W_{2 i}} \frac{W_{1 i}}{\varepsilon_{i}^{2}}\left[\mu \delta W_{2 i}-W_{2 i}^{2}\right], \quad i=M, F
$$

whereby the first-order condition (f.o.c.) w.r.t. $W_{2 i}$ implies that the wage paid in equilibrium to male and female workers is identical: 12

$$
W_{2}^{*}=\mu \delta / 2
$$

and by replacing $W_{2}{ }^{*}$ into the bracketed term in (A.2.6), the firm 's profit in period $2\left(\Pi_{2 \mathrm{i}}^{*}\right)$ is given by $\Pi_{2 \mathrm{i}}^{*}=W_{1 i}^{2}(\mu \delta)^{2} / 4 \varepsilon_{i}^{2}$.

Going back to period 1, firms will choose $W_{1 \mathrm{i}}$ to maximize the sum of expected profits in both periods, subject to the participation constraint in that period, i.e.

\footnotetext{
${ }^{12}$ This is just the average of the worker' s productivity ${ }^{\prime}$ and the outside wage which is assumed to be zero. The weight $1 / 2$ in the average is due to the choice of the uniform distribution in the illustration. Alternative distributions will give rise to a weighted average with unequal weights.
} 


$$
\max _{W_{1 i}}\left\{\frac{1}{\varepsilon_{i}} \int_{0}^{W_{1 i}}\left(\delta-W_{1 i}\right) d \omega+\frac{W_{1 i}^{2}}{4 \varepsilon_{i}^{2}}(\mu \delta)^{2}\right\}, \quad i=M, F
$$

which implies that:

$$
W_{1 i}^{*}=\frac{\delta}{2}+\frac{(\mu \delta)^{2}}{8 \varepsilon_{i}}
$$

Since $\varepsilon_{F}>\varepsilon_{M}$, it follows that $W_{1 M}^{*}>W_{1 F}^{*}$. Given that, for the same $\delta, W_{2 M}^{*}=W_{2 F}^{*}$, it follows that the return to tenure $\left(W_{2 i}^{*}-W_{1 i}^{*}\right)$ is higher for women than for men.

Non-PP jobs can be interpreted in terms of this model as implying that $\mu=1$, that is, a flatter wage profile. From (A.2.7) and (A.2.8) with $\mu=1$, we get that wages in non-PP jobs are lower than in PP jobs. 
Figure 1. Gender wage gaps (Total, Non-PP and PP components)

- Whole Sample (in percent)-

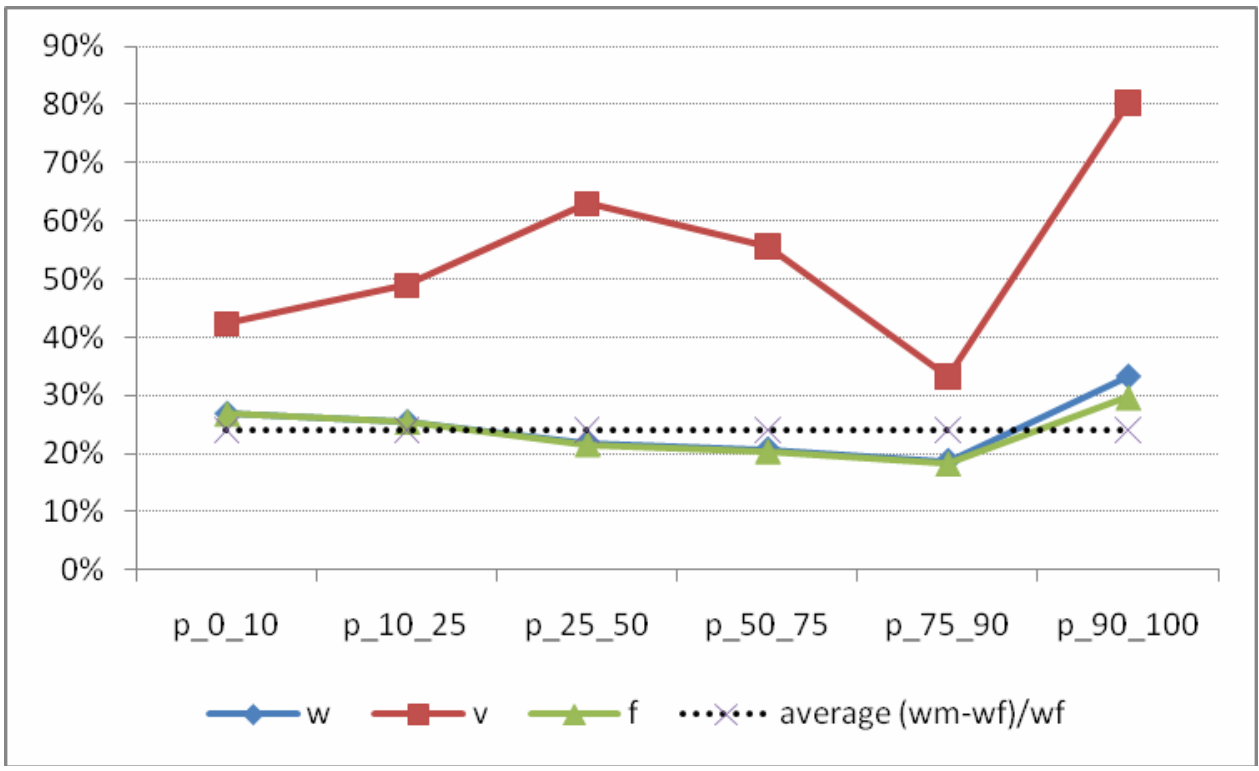

Figure 2. Gender wage gaps and the contribution of PP component - Sample of PP workers (in percent)-

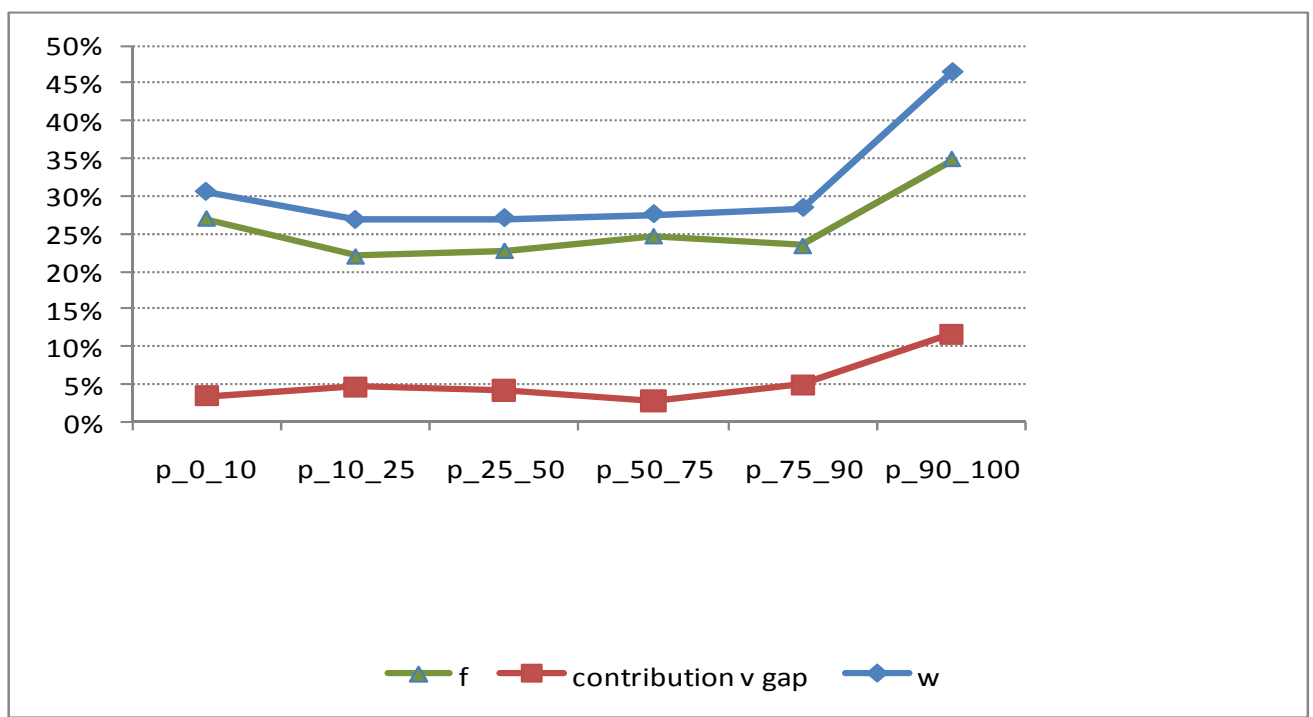


Table 1 - Sample characteristics (Full-time workers between 18-65 years)

\begin{tabular}{lcc}
\hline Variables & Women $(65,233)$ & Men $(129,930)$ \\
\hline & & Mean \\
\hline Individual Characteristics & & \\
\hline Education & & \\
Primary or less & 0.176 & 0.275 \\
Secondary & 0.508 & 0.545 \\
University & 0.316 & 0.180 \\
Age & & \\
Less 30 years & 0.257 & 0.200 \\
31-40 & 0.354 & 0.323 \\
41-50 & 0.245 & 0.265 \\
$>50$ & 0.143 & 0.212 \\
Tenure (years) & 7.410 & 8.867 \\
Permanent Contract & 0.727 & 0.768 \\
Wages & & \\
Total Hourly Wage (logs) & 2.185 & 2.391 \\
Performance Pay & & \\
\% PP job & 0.227 & 0.227 \\
Total Hourly PP (only PP workers) & 1.127 & 1.958 \\
Firm Characteristics & & \\
Size & & \\
$<50$ workers & 0.339 & 0.403 \\
51-200 workers & 0.265 & 0.288 \\
>200 workers & 0.396 & 0.309 \\
Firm Bargaining Agreement. & 0.163 & 0.194 \\
Exporting firms & 0.163 & 0.194 \\
\hline S & &
\end{tabular}

Source: EES (2006) 
Table 2a: Characteristics of workers and firms by type of job and gender

\begin{tabular}{|c|c|c|c|c|}
\hline & \multicolumn{2}{|c|}{ Worker with PP } & \multicolumn{2}{|c|}{ Workers w/o PP } \\
\hline & $\begin{array}{c}\text { Women } \\
\text { (14789 obs.) }\end{array}$ & $\begin{array}{c}\text { Men } \\
\text { (29460 obs.) }\end{array}$ & $\begin{array}{c}\text { Women } \\
\text { (50444 obs.) }\end{array}$ & $\begin{array}{c}\text { Men } \\
\text { (100470 obs.) }\end{array}$ \\
\hline Variables & Mean & Mean & Mean & Mean \\
\hline \multicolumn{5}{|l|}{ Education } \\
\hline Primary or less & 0.107 & 0.178 & 0.196 & 0.304 \\
\hline Secondary & 0.494 & 0.545 & 0.512 & 0.545 \\
\hline University & 0.399 & 0.277 & 0.292 & 0.151 \\
\hline \multicolumn{5}{|l|}{ Age } \\
\hline Less 30 years & 0.204 & 0.149 & 0.273 & 0.215 \\
\hline $31-40$ & 0.381 & 0.313 & 0.346 & 0.325 \\
\hline $41-50$ & 0.265 & 0.294 & 0.239 & 0.257 \\
\hline$>50$ & 0.150 & 0.244 & 0.141 & 0.203 \\
\hline Tenure (years) & 9.281 & 12.037 & 6.861 & 7.938 \\
\hline Indefinite Contract & 0.814 & 0.862 & 0.741 & 0.741 \\
\hline \multicolumn{5}{|l|}{ Firm Characteristics } \\
\hline \multicolumn{5}{|l|}{ Size } \\
\hline$<50$ workers & 0.201 & 0.235 & 0.380 & 0.452 \\
\hline 51-200 workers & 0.239 & 0.297 & 0.272 & 0.285 \\
\hline >200 workers & 0.560 & 0.467 & 0.348 & 0.262 \\
\hline \multicolumn{5}{|c|}{ Collective Bargaining(ref: Industry level) } \\
\hline Firm Bargaining Agr. & 0.193 & 0.288 & 0.154 & 0.167 \\
\hline \multicolumn{5}{|c|}{ Firm Market (ref: non-exp .firms) } \\
\hline Exporting firms & 0.231 & 0.261 & 0.135 & 0.153 \\
\hline
\end{tabular}


Table 2b: Incidence of PP by industry and occupation

\begin{tabular}{lccc}
\hline & Mean & Std. Dev. & No. Obs. \\
\hline Industries & & & \\
Mine \& Extractive Ind. & 0.188 & 0.391 & 2919 \\
Manufactures & 0.205 & 0.404 & 74332 \\
Energy & 0.324 & 0.468 & 4627 \\
Construction & 0.127 & 0.333 & 17096 \\
Retail trade & 0.241 & 0.427 & 17131 \\
Hotels and Restaurants & 0.123 & 0.328 & 8315 \\
Transportation & 0.324 & 0.468 & 12710 \\
Financial Intermediation & 0.598 & 0.490 & 10475 \\
Real State and Res. Serv. & 0.194 & 0.395 & 16342 \\
Education & 0.092 & 0.289 & 7998 \\
Health & 0.287 & 0.452 & 14178 \\
Other Services & 0.146 & 0.353 & 9040 \\
Occupations & & & \\
Managers & 0.497 & 0.500 & 6190 \\
Professionals & 0.288 & 0.453 & 20295 \\
Technicians & 0.326 & 0.469 & 30184 \\
Clerks & 0.257 & 0.437 & 24761 \\
Personal Services & 0.196 & 0.397 & 17528 \\
Agriculture and Fisheries & 0.146 & 0.353 & 542 \\
Craftsmen & 0.169 & 0.375 & 37918 \\
Operators and Assemblers & 0.180 & 0.384 & 34822 \\
Laborers, non-qualified & & & 22923 \\
operators & 0.127 & 0.333 & \\
\hline
\end{tabular}


Table 2c: Share of women throughout the PP distribution

\begin{tabular}{lc}
\hline & $\begin{array}{c}\text { \% Women in } \\
\text { percentile }\end{array}$ \\
\hline [p0-p10] & $40.6 \%$ \\
[p11-pw25] & $40.3 \%$ \\
[p26-pw50] & $39.5 \%$ \\
[p51-pw75] & $32.0 \%$ \\
[p76-pw90] & $24.8 \%$ \\
[p91-pw95] & $18.6 \%$ \\
\hline [p95-pw100] & $15.9 \%$ \\
\hline
\end{tabular}

Table 3a: Hourly wages for PP and non-PP Workers

\begin{tabular}{|c|c|c|c|c|c|c|}
\hline & \multicolumn{4}{|c|}{ PP } & \multicolumn{2}{|c|}{ Non-PP } \\
\hline & \multicolumn{2}{|c|}{ Women } & \multicolumn{2}{|c|}{ Men } & Women & Men \\
\hline & $\begin{array}{c}\text { Total } \\
\text { Hourly } \\
\text { Wage }(€)\end{array}$ & $\begin{array}{c}\text { Ratio } \\
\text { PP/Total } \\
\text { Wage (\%) }\end{array}$ & $\begin{array}{c}\text { Total } \\
\text { Hourly } \\
\text { Wage(€) }\end{array}$ & $\begin{array}{l}\text { Ratio } \\
\text { PP/Total } \\
\text { Wage(\%) }\end{array}$ & $\begin{array}{c}\text { Total } \\
\text { Hourly } \\
\text { Wage }(€)\end{array}$ & $\begin{array}{c}\text { Total } \\
\text { Hourly } \\
\text { Wage(€) }\end{array}$ \\
\hline Average & 14.503 & 7.164 & 19.144 & 9.012 & 9.678 & 11.665 \\
\hline $\mathrm{P} 10^{\text {th }}$ & 6.060 & 0.976 & 7.801 & 0.009 & 3.721 & 4.689 \\
\hline $\mathrm{P} 25^{\text {th }}$ & 8.577 & 2.087 & 10.804 & 0.025 & 5.884 & 7.308 \\
\hline $\mathrm{P} 50^{\text {th }}$ & 12.479 & 4.657 & 16.051 & 0.060 & 8.126 & 9.826 \\
\hline $\mathrm{P} 75^{\text {th }}$ & 18.800 & 9.491 & 23.546 & 0.127 & 12.048 & 14.192 \\
\hline $\mathrm{P}^{\text {th }}$ & 24.842 & 16.684 & 33.127 & 0.217 & 17.795 & 20.162 \\
\hline
\end{tabular}


Table 3b: Hourly wage components for workers with PP (in €)

\begin{tabular}{|c|c|c|c|c|}
\hline & & Women & Men & \\
\hline & $\begin{array}{c}\text { PP } \\
\text { wage }\end{array}$ & $\begin{array}{l}\text { Other wage } \\
\text { components }\end{array}$ & $\begin{array}{c}\text { PP } \\
\text { wage } \\
\end{array}$ & $\begin{array}{l}\text { Other wage } \\
\text { components }\end{array}$ \\
\hline Average & 1.127 & 13.376 & 1.958 & 17.186 \\
\hline $\mathrm{P} 10^{\mathrm{th}}$ & 0.102 & 5.648 & 0.132 & 7.031 \\
\hline $\mathrm{P} 25^{\text {th }}$ & 0.225 & 7.850 & 0.324 & 9.675 \\
\hline $\mathrm{P} 50^{\text {th }}$ & 0.539 & 11.679 & 0.890 & 14.758 \\
\hline P75 & 1.311 & 17.509 & 2.198 & 21.694 \\
\hline $\mathrm{P}^{\text {th }}$ & 2.594 & 22.828 & 4.493 & 29.597 \\
\hline
\end{tabular}


Table 4: Log hourly wage regressions

Dependent Variable: Log Hourly Total Wage

(1) (2) (3)

PP Workers Non-PP Workers Pooled

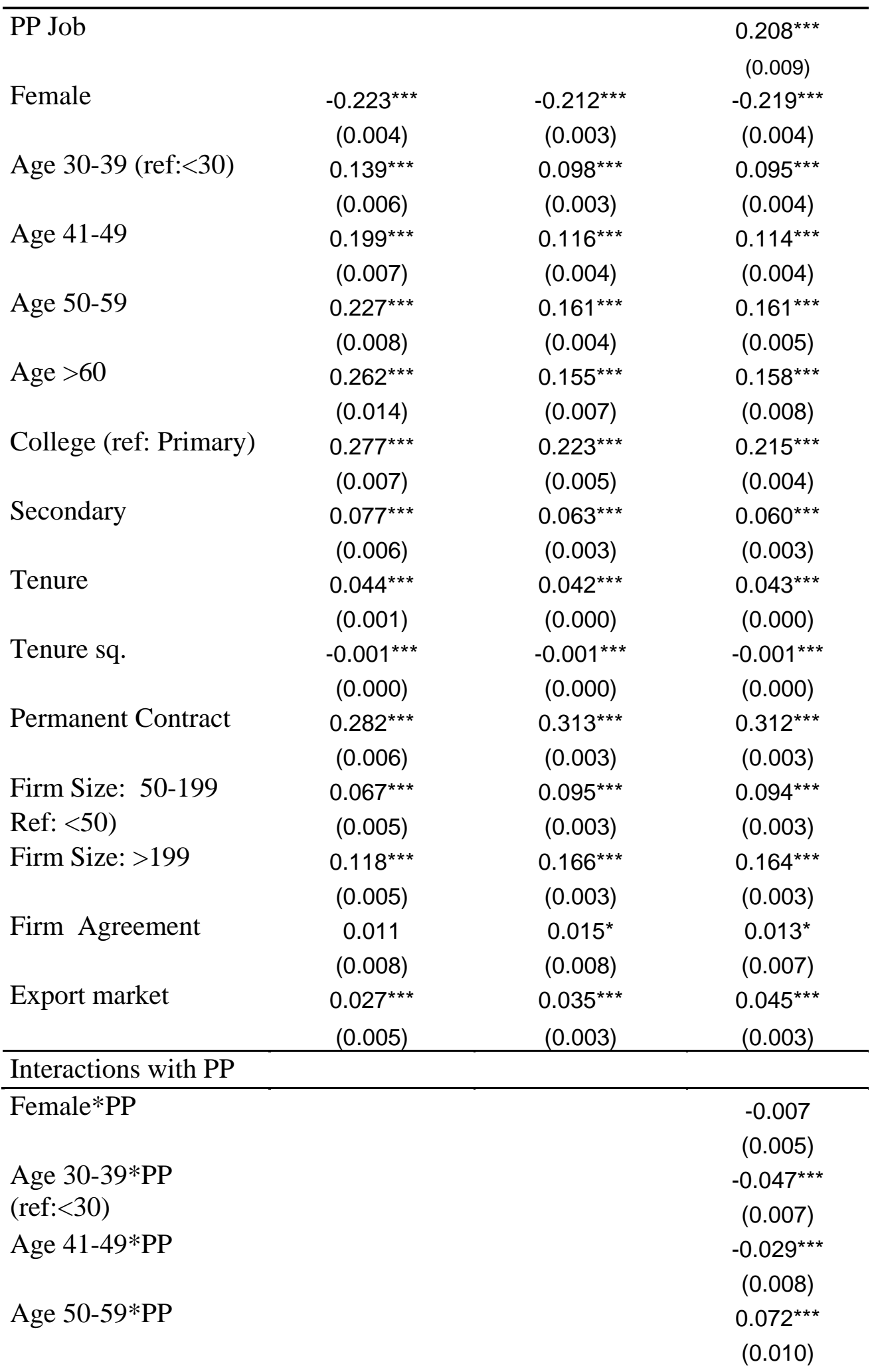


Age $>60 * \mathrm{PP}$

College*PP (ref:

Primary)

Secondary*PP $0.030^{\star \star \star *}$

Tenure*PP

Permanent

Contract*PP

$-0.025^{\star \star \star}$

$(0.007)$

Firm Size: $(r e f<50)$

50-199*PP

Firm Size: >199*PP

Firm Agreement*PP

Export. Firm *PP

\begin{tabular}{lccc} 
No. Observations & 44249 & 150914 & 195163 \\
\hline R sq. & 0.605 & 0.511 & 0.573 \\
\hline
\end{tabular}

Note: S.e's. in parentheses. Estimations also control for industry dummies (11), occupational dummies (8) and regional dummies (17). 
Table 5: Probit estimation

Dependent Variable: Receiving Performance Pay (1/0)

(1)

(2)

Female

$-0.047^{\star \star \star}$

$-0.103^{\star \star *}$

Age 30-39 (ref:<30)

$(0.008)$

$(0.016)$

$0.052^{\star \star *}$

$0.016^{\star \star}$

$(0.010)$

(0.008)

Age 41-49

$0.032^{* \star *}$

0.002

$(0.011)$

$(0.013)$

Age 50-59

0.015

$-0.010$

$(0.013)$

(0.015)

Age $>60$

$-0.076^{\star \star *}$

$-0.099^{\star * \star}$

University (ref: Primary)

(0.023)

$(0.026)$

0.260 ***

$0.262^{\star \star *}$

(0.013)

(0.013)

Secondary

$0.164^{\star \star \star}$

$0.161^{\text {** }}$

Tenure

(0.009)

(0.009)

0.030 ***

$0.031^{\star \star *}$

Tenure square

$(0.001)$

$(0.001)$

$-0.001^{\star \star \star}$

$-0.001^{\star \star \star}$

$(0.000)$

$(0.000)$

Permanent Contract

$0.037^{\star \star \star}$

$0.035^{\star \star \star}$

(0.010)

(0.010)

Firm Size: 50-199

$0.295^{\star \star \star}$

$0.301^{\star * \star}$

Ref: <50)

(0.009)

(0.009)

Firm Size: >199

$0.485^{\star \star \star}$

$0.478^{\star \star \star}$

(0.008)

(0.009)

$0.096^{\star *}$

0.120 ***

(0.009)

(0.009)

Exporting firm

$0.122^{\star \star \star}$

$0.120^{\star \star \star}$

(0.009)

(0.011)

Interactions with female

Age 30-39*Female (ref:<30)

$-0.047 * * *$

Age 41-49*Female

$(0.019)$

$-0.031 * * *$

(0.011)

Age 50-59*Female

$0.072 * * *$

(0.024)

0.062

Age $>60 *$ Female

(0.052)

No. Observations

Pseudo $\mathrm{R}^{2}$

0.123 


\section{Table 6: Estimates of alternative specifications of log hourly wage equation corrected for selectivity}

Dependent Variable: log PP wage component

(1)

\begin{tabular}{|c|c|c|c|c|c|}
\hline & OLS & $\begin{array}{l}\text { Heckman } \\
\text { selection }\end{array}$ & $\begin{array}{l}\text { Within } \\
\text { Firm }\end{array}$ & $\begin{array}{c}\text { Within } \\
\text { Occupations }\end{array}$ & $\begin{array}{c}\text { Within } \\
\text { Firm- } \\
\text { Occupation }\end{array}$ \\
\hline Female & $\begin{array}{c}-0.407^{* * *} \\
(0.014)\end{array}$ & $\begin{array}{c}-0.453^{* * *} \\
(0.018)\end{array}$ & $\begin{array}{c}-0.343^{* * *} \\
(0.011)\end{array}$ & $\begin{array}{c}-0.434^{* * *} \\
(0.019)\end{array}$ & $\begin{array}{c}-0.290 * * * \\
(0.011)\end{array}$ \\
\hline Age 30-39 (ref:<30) & $\begin{array}{c}0.257^{* * *} \\
(0.019)\end{array}$ & $\begin{array}{c}0.337^{* * *} \\
(0.024)\end{array}$ & $\begin{array}{c}0.181^{* * *} \\
(0.018)\end{array}$ & $\begin{array}{c}0.281^{* * *} \\
(0.024)\end{array}$ & $\begin{array}{c}0.143^{* * *} \\
(0.017)\end{array}$ \\
\hline Age $41-49$ & $\begin{array}{c}0.334^{* * *} \\
(0.022)\end{array}$ & $\begin{array}{c}0.381^{* * *} \\
(0.026)\end{array}$ & $\begin{array}{c}0.252^{* * *} \\
(0.019)\end{array}$ & $\begin{array}{c}0.313^{* * *} \\
(0.027)\end{array}$ & $\begin{array}{c}0.192^{* * *} \\
(0.019)\end{array}$ \\
\hline Age 50-59 & $\begin{array}{c}0.326^{* * *} \\
(0.026)\end{array}$ & $\begin{array}{c}0.353^{* * *} \\
(0.031)\end{array}$ & $\begin{array}{c}0.238^{* * *} \\
(0.022)\end{array}$ & $\begin{array}{c}0.298^{* * *} \\
(0.031)\end{array}$ & $\begin{array}{c}0.184^{* * *} \\
(0.021)\end{array}$ \\
\hline Age $>60$ & $\begin{array}{c}0.601^{* * *} \\
(0.044)\end{array}$ & $\begin{array}{c}0.532^{* * *} \\
(0.052)\end{array}$ & $\begin{array}{c}0.416^{* * *} \\
(0.037)\end{array}$ & $\begin{array}{c}0.395^{* * *} \\
(0.053)\end{array}$ & $\begin{array}{c}0.311^{* * *} \\
(0.036)\end{array}$ \\
\hline College (ref: Primary) & $\begin{array}{c}0.793^{* * *} \\
(0.020)\end{array}$ & $\begin{array}{c}0.350 * * * \\
(0.064)\end{array}$ & $\begin{array}{c}0.362^{* * *} \\
(0.128)\end{array}$ & $\begin{array}{c}0.636^{* * *} \\
(0.053)\end{array}$ & $\begin{array}{c}0.280^{* * *} \\
(0.062)\end{array}$ \\
\hline Secondary & $\begin{array}{c}0.109 * * * \\
(0.018)\end{array}$ & $\begin{array}{c}0.380 * * * \\
(0.035)\end{array}$ & $\begin{array}{l}0.010^{* *} \\
(0.064)\end{array}$ & $\begin{array}{c}0.213^{* * *} \\
(0.029)\end{array}$ & $\begin{array}{c}0.043 \\
(0.035)\end{array}$ \\
\hline Tenure & $\begin{array}{c}0.023^{* * *} \\
(0.002)\end{array}$ & $\begin{array}{c}0.061^{* * *} \\
(0.005)\end{array}$ & $\begin{array}{c}0.019 * * * \\
(0.005)\end{array}$ & $\begin{array}{c}0.060^{* * *} \\
(0.005)\end{array}$ & $\begin{array}{c}0.0173^{* * *} \\
(0.006)\end{array}$ \\
\hline Tenure square & $\begin{array}{c}-0.001^{* * *} \\
(0.000)\end{array}$ & $\begin{array}{c}-0.001^{* * *} \\
(0.000)\end{array}$ & $\begin{array}{c}-0.001^{* * *} \\
(0.000)\end{array}$ & $\begin{array}{c}-0.001^{* * *} \\
(0.000)\end{array}$ & $\begin{array}{c}-0.000 * * * \\
(0.000)\end{array}$ \\
\hline Permanent Contract & $\begin{array}{c}0.450^{* * *} \\
(0.020)\end{array}$ & $\begin{array}{c}0.534^{* * *} \\
(0.024)\end{array}$ & $\begin{array}{c}0.389 * * * \\
(0.021)\end{array}$ & $\begin{array}{c}0.443^{* * *} \\
(0.024)\end{array}$ & $\begin{array}{c}0.362^{* * *} \\
(0.021)\end{array}$ \\
\hline $\begin{array}{l}\text { Firm Size: 50-199 } \\
\text { Ref: <50) }\end{array}$ & $\begin{array}{c}-0.126^{* * *} \\
(0.018)\end{array}$ & $\begin{array}{c}0.236^{* * *} \\
(0.045)\end{array}$ & & $\begin{array}{c}0.317^{* * *} \\
(0.048)\end{array}$ & \\
\hline Firm Size: >199 & $\begin{array}{c}-0.209 * * * \\
(0.017)\end{array}$ & $\begin{array}{c}0.366^{* * *} \\
(0.068)\end{array}$ & & $\begin{array}{l}0.505^{* * *} \\
(0.0726)\end{array}$ & \\
\hline Firm Agreement & $\begin{array}{l}-0.019 \\
(0.016)\end{array}$ & & & & \\
\hline Exporting firm & $\begin{array}{c}0.114^{* * *} \\
(0.016)\end{array}$ & $\begin{array}{c}0.262^{* * *} \\
(0.024)\end{array}$ & & $\begin{array}{c}0.263^{* * *} \\
(0.023)\end{array}$ & \\
\hline Inv. Mills Ratio & & $\begin{array}{c}1.628^{* * *} \\
(0.170)\end{array}$ & $\begin{array}{c}1.693^{* * *} \\
(0.198) \\
\end{array}$ & $\begin{array}{c}1.984^{* * *} \\
(0.141)\end{array}$ & $\begin{array}{c}1.513 * * * \\
0.474)\end{array}$ \\
\hline No. Obs. & 44249 & 195163 & 44249 & 44249 & 44249 \\
\hline R sq. & 0.186 & 0.175 & 0.115 & 0.089 & 0.125 \\
\hline
\end{tabular}


Table 7: Adjusted gender wage gaps - Quantile regressions (with selection correction)

Dependent Variable: Log PP Hourly Wage

\begin{tabular}{lccccc}
\hline & $(1)$ & $(2)$ & $(3)$ & $(4)$ & $(5)$ \\
& P10th & P25th & P50th & P75th & P90th \\
& & & & \\
\hline Female $(\mathrm{WFO})$ & $-0.202^{* *}$ & $-0.272^{* * *}$ & $-0.301^{* * *}$ & $-0.354^{* * *}$ & $-0.433^{* * *}$ \\
& $(0.022)$ & $(0.020)$ & $(0.014)$ & $(0.016)$ & $(0.019)$ \\
\hline
\end{tabular}

Note: s.e's. in parentheses. Estimations also control for the whole set of covariates (age, education, tenure, type of contract) as well as regional dummies and firm \& occupational fixed effects (WFO). 
Table 8: Decomposition of (log) hourly gap in PP

\begin{tabular}{ccc}
\hline \multicolumn{3}{c}{ Unadjusted Gender Wage Gap in PP: 46 log-points } \\
\hline & Absolute [relative] & Absolute [relative] \\
Contribution of Diff. & Contribution of Diff. \\
in Characteristics & in Returns \\
Variables & $\left(\mathrm{X}_{\mathrm{m}-} \mathrm{X}_{\mathrm{f}}\right)^{*} \beta_{\mathrm{m}}$ & $\left(\beta_{\mathrm{m}}-\beta_{\mathrm{f}}\right)^{*} \mathrm{X}_{\mathrm{f}}$ \\
\hline Sample Selection & 0.62 & -1.56 \\
Tenure & {$[1.34 \%]$} & {$[-3.39 \%]$} \\
& 3.44 & -1.93 \\
Education & {$[7.47 \%]$} & {$[-4.19 \%]$} \\
& -2.82 & 3.83 \\
Age & {$[-6.13 \%]$} & {$[8.33 \%]$} \\
& 1.35 & 8.46 \\
Type of Contract & {$[2.93 \%]$} & {$[18.39 \%]$} \\
& 1.02 & 2.42 \\
Occup. and Firm & {$[2.22 \%]$} & {$[5.26 \%]$} \\
Effects & 1.81 & 3.36 \\
Constant & {$[3.93 \%]$} & {$[7.30 \%]$} \\
& & 26.0 \\
Total & 5.42 & {$[56.52 \%]$} \\
& {$[11.8 \%]$} & 40.58 \\
& & {$[88.2 \%]$}
\end{tabular}

Note: Oaxaca-Blinder decomposition based on WFO estimation for men and women allowing for different returns by gender. 